From the Department of Child Health, Medical School, University of Airlaingga, Sunabaya

\title{
Diagnosis of Pulmonary Tuberculosis in Children
}

\author{
by
}

GUNADI SANTOSA

\section{Abstract}

1. A definite diagnosis of tuberculosis can only be established on the basis of the finding of the tubercle bacilli.

2. The isolation of the mycobacterium tuberculosis from a child is subject to difficulties:

a. the necessity of gastric lavage for 3 consecutive days, which is difficult to perform ambulatory.

b. the mecessity of the proper facilities of a microbiologic labonatory.

c. the outcome is often not sufficiently high.

3. It is concludied that at the moment making of the bacteriological diagnosis of child tuberculosis is not practical, so that we are forced to depend on the clinicial diagnosis.

4. The tuberculin test is very important in establishing the diagnosis. It is recommended to perform this test routinely on every child once a year and also that every medical doctor as well as specialist performs this test to detect a case of TBC at the leartiest possible moment. 
5. It is greatly recommended to improve the tuberculin solution by the administration of a buffiered solvent and Tweien 80 which are alneiady commonly used abroad.

6. Another recommendation is the finding of the source of infection in all radults with whom the child with TBC associates. Also the examination of all childrem who come into contact with a TBC patient is recommended.

7. It is advisable to perform a routine check-up once a year on all adults whose activities are closely related to childrem, e.g. teachers, nurses, trainers, etc.

8. $B C G$ vaccination complicates the interpretation of a tuberculin test.

9. Due to the fact that source of infection tat this moment is stinl prevalent and $B C G$ is administered directly, there is stint the possibility of tuberculosis in children with a $B C G$ scar, even though $B C /$ was administered during the neonatal period. 


\section{Introduction}

Tuberculosis is classified into two types

\section{a. Primary tuberculosis: primary effect/complex with its complica- tions.}

\section{b. Post primary tuberculosils.}

Primary tuberculosis is mast common found in children, but post primary TBC is more rarely seen in children. In this paper primary tuberculosis will be further discussed. There is a significant difference between primary TBC and post primary TBC. In primary TBC a hematogenous dissemination process to other parts of the body might occur in the very beginning; it could even happen before the development of a hypersensitivity to tuberculin. In posit primary TBC the process is more restricted to the lungs, where the distrilbution is bronchogenous. It is for this reason that primary TBC as a disease, which is not without danger, necessitates the establishment of a diagnosis at the earliest possible moment. Moreover, primary TBC is never, to be underestimated even if there are indicaitions minimal or no abnormalities on the chest roenitgenogram. This, because of the passible occurrence of complications, is not determined by the severity of the hung abnormalities.

\section{Review of diagnostic elements}
A. Anamnesis

B. Evidence of the source of infection

C. Physical examination

D. Manitoux test

E. Roentgenogram

F. Bacteriological examination

A. Anamnesis. The dilagmosis of TBC is made by assumption, that complaints ccmmonly encountered are : long-lasting fever, chronic cough, loss of weight, loss of energy, etc. These symptoms point to TBC but they are not pathognomonic. Haemoptoe is rare among children. Our partients showed only $0.7 \%$ with haemoptoe:

B. Evidence of the source of infection. Since we are dealing with primary TBC the source of infection should have occurred several months before, so that during the examination no source of infection could be determined. The evidence of the source of infection is very helpful in determining the diagnosis, so that it is very important to examine every adult with whom the child has been in close contact. Also ail children who have been in contract with a known adult TBC patient have to be examined. It is not uncommon to find children with TBC, whose parents are treated at BP4 or at Puskesmas (Public Heailh Centers), while their children have never been examined or vaccinated. It is worthwhile to perform a routine check-up once a year on all adults who have a close con. 
tact with children, for instance teachers, numses, servants, etc.

Finding the source of infection has two signifficances:

1. important in determining the diagnosis, and

2. necessary for the success of the therapy (it should be isolated and treated simultaneously).

C. Physsical examination. Primary TBC is mostly asymptomatic; its symptoms are usually rather obscure. When symptoms are manifest, usually the process is already far advanced or complications have already appeared, such as pneumonia, emphysema, atelectasis, pleural effusion, etc. These abnormalities are not pathognomonic for Koch Pulmonum, because they can be caused by various reasons. As primary TBC can disiseminate very eassily, we have to look in physical examination for extrathoracic ttubercular lesions, e.g. scrophuloderma, glandular enlargement, cold abscess, TBC of the bones and joints, serous meningitis, tubercle in the choroid plexus of the eye, conjunctivitis phlyctaenularis, etc.

D. Mantoux test. The Mantoux test is very important in determining the diagnosis of tuberculosis in children. In performing the Mantoux test routinely, TBC in children can be detected lat the earliest possible moment. As a sitandard PPD 5 TU or OT 0.1 is used.
Interpretation of the results of the Mantoux test:

a. Induration of $10 \mathrm{~mm}$ or more $=$ posittive reaction.

Clinically it means that a person is or has been infected by the $M$. tuberculasis.

b. Induration of $5 \mathrm{~mm}$ to $9 \mathrm{~mm}=$ doubitful reaction.

Clinically it means a possible error or an infection by $M$. tuberculosis or a cross reaction with an atypical mycobacterium, or post $B C G$ vaccination. It is necessary to repeat the test with the same concentration. If the second reaction becomes $10 \mathrm{~mm}$ or more than it means an infection by the M. tuberculosis. If it remains 6-9 $\mathrm{mm}$ it means a cross reaction or post BCG vaccination; if it is 6-9 mim but accompanied' by other clear indrications of TBC then it has to be regarded as a possible infection by M. tuberculosis.

c. Induration of 0 to $4 \mathrm{~mm}=$ negative reaction.

Clinfically it means that there is no infection by the M. tuberculosis; repetition is unnecessary, except if there is a strong suspicion of the presence of tuberculosils.

The use of OT $1 \mathrm{mg}$ or PPD 250 TU is considered to be very useful especially for the need of mass case-finding, despite the possibility of a noin-specific reaction 
(Lilem Tjai Tire, 1955). A positive Mantoux test usually indicates TBC in the present or in the past. A positive Mantoux test indicates an active infectilon of TBC if:

a. the patient is less than 3 years of age and has not receive a previous $B C G$ vaccination and anti TBC therapy. This is based on the assumption that the process of primary TBC will clinically recover in 3-5 years.

b. there is a conversion of the Mantoux test from negative to positive during the last year and the patient has neither received any $B C G$ vaccination nor anti TBC drugs. The interpretation of conversion is actually also difficult. Generally if a negative Mantoux test becomes positive it is considered as a conversion. But when a Mantoux test of $9 \mathrm{~mm}$ changes into $10 \mathrm{~mm}$, is it then considered as a conversion? This should be considered because of the possibility of error in reading the Mantoux reaction which ranges between 1-2 mm. Griep (1960) found that a Mantoux conversion only becomes siignificant if the first Mantoux test produced an induration of 0 to $2 \mathrm{~mm}$, and has increased at least $10 \mathrm{~mm}$. Generallity, after finding a posibive Mantoux test, we have to determine whether the procesis is active or non-active by observing the ; signs of activity of the TBC process, which are the presence of acid-fast bacilli, infiltration or swelling of the glands on the X-ray photo, longlasting-fever which is not caused by other processes, losis of weight, a high BSR, and loss of energy.

The following must also be kept in mind:

- False positive reaction: a posittive Mantoux test reaction without any previous infection of $\mathrm{TBC}$; it can be found in infections by an atypical mycobacterium, or after BCG vaccination.

- Falise negative reaction: a negative Mantoux reaction even lif there is or has been an infection of TBC; it can be found in the following conditions:

* pre-allergic period: 2-10 weeks

* severe TBC: meningitis, miliary TBC

* severe malnutrition (kwashiorkor)

- dehydration

* morbilli, lasting from 10 days to 6 weeks

* pertussis

* morbilli vaccination, also lasting from 10 days to 6 weeks

* severe rubella, for 1-3 weeks

* typhus abdominalis 
* diseases accompanied by high fever

* administration of corticosteroid

* administration of immunosuppressive drugs

Due to the presence of a pre-allergic period lasting about 2-10 weeks, a person is said ito be free of infection if the repetiltion of his Mantoux test produces la negative results as early as 10 weeks after separation from the source of infection (Kendig, 1972). A tuberculin test can only be well evaluated if it is performed according to some specific requirements.

Storage and dellivery of tuberculin materials must be in a refrigerated condition. For Alt tuberculin PN Biofarma Bandung recommends storage in a itemperature of about $4^{\circ} \mathrm{C}$. But unfortunately enough the delivery of this material from Bandung to Surabaya has been done in plain cartons and carried on trucks so that protection from the heat of the sun was unlikely. The use of a proper solvent must also be obser- ved : isottonic phosphate buffered salline with a pH of 7.38; and the utilization of stabilizer Tween 80 $(0.0005 \%$ of polyoxyethylene sorbitan monooleate) to prevent the lowering of tuberculin concentration due to the absorption of the glass or plastic container (Landi et al., 1971).

Unfortunately, these two substances are not distributed along with tuberculin availiable here. To cope with the tuberculosis problems mentioned above we only use fresh tubercullin solution and only for approximately 4 hours (8 to 12 a.m.). Examination of the Mantoux test should be done routinely by every doctor on every child in order to detect TBC as early as possible, starting at the age of 6-8 moniths and afterwards repeated once a year. When there is a contact with an infectious source a Mantoux test should be performed immediately, and if the resullt is negative it must be repeated after 10 weeks; and if the subject remains in close association with the source then a Mantoux test is to be repeated every three months.

TABLE I : Mantoux test performed an 857 children with $T B C$ at the Dr. Soetomo Hospital, Surabaya (1971 - 1974).

\begin{tabular}{|c|c|c|c|c|}
\hline & Total patients & Miliary TBC & Meningitis & $\begin{array}{c}\text { Bone \& } \\
\text { joint } \mathrm{TBC}\end{array}$ \\
\hline Positive & 809 & 45 & 73 & 97 \\
\hline Mantoux test & $(94.4 \%)$ & $(52.9 \%)$ & $(85.9 \%)$ & $(99.0 \%)$ \\
\hline Negative & 48 & 40 & 12 & 1 \\
\hline Mantoux test & & & & \\
\hline
\end{tabular}


The above table shows that $94.4 \%$ of the patients had a positive Mantoux test. Onlly $52.7 \%$ of the patients with miliary TBC had a positive test due to the severe TBC and most of them were also malnourished.

The interpretation of the Mantoux tesit of children who have had BCG vaccination is a difficult problem. It is known that the measurement of the induration of a Mantoux test posit BCG vaccination is variable (Raju, Mehta, 1970). For the sake of establishing a diagnosis, it is necesisary to know whether a Mantoux test post BCG vaccination can still be used to determine whether there is an active infection of $M$. tuberculosis or just a BCG vaccination. Kendig (1972) Istated that BCG generally produces an induration between 5 - $9 \mathrm{~mm}$. If the induration exceeds $15 \mathrm{~mm}$ the presence of an active infection should be isuspected. Lotte (1971) carried out investigations in several European countries and found that if the difference of the measurements of posit-BCG Mantoux induration exceeds $18 \mathrm{~mm}$, it indicates an active infection.

Hasan and Han Sik Lilang (1964) in a sample survey carried out in the Mallang disitrict found that $65 \%$ of Mantoux test post-BCG gave an induration of $10-15 \mathrm{~mm}$, whereas $35 \%$ gave an induration larger than $\mathbf{1 5}$ $\mathrm{mm}$. According to Blicker (1966), a past-BCG Manitoux itest produced a variability lof indurations ranging from $0-20 \mathrm{~mm}$. They formed a unimodlal curve so that it was impossible ito differentiate between posilitive and negative or between a M. tuberculosis infection and BCG. Azuma (1972) also said that the measurements of indurations of past-BCG Mantoux tests were variable, i.e. causing difficulties to evaluate the tests after BCG vaccination. There were 115 TBC patients with a BCG scar.

TABLE 2: BCG scar on tuberculosis patients

\begin{tabular}{lcccc}
\hline & No. of patients & Miliary TBC & Meningitis $\begin{array}{c}\text { Bones \& } \\
\text { joints TBC }\end{array}$ \\
\hline BCG scar + & $115(13.4 \%)$ & $8(9.4 \%)$ & $5(5.9 \%)$ & $19(19.44 \%)$ \\
\hline $\begin{array}{l}\text { BCG at } \\
\text { neonatal period }\end{array}$ & 7 & 0 & 0 & 0 \\
\hline BCG scar - & 742 & 77 & 80 & 79 \\
\hline T o t a 1 & 857 & 85 & 85 & 98 \\
\hline
\end{tabular}


This table - 2 shows that the presence of a BCG scar in a child does not exclude the possibility of the diagnasis of ${ }^{*} \mathrm{TBC}$, even severe complications might be found as well. A BCG vaccination during the neonatal pertiod could also not exclude the diagnosis of TBC. This is due to the fact that BCG is performed direatly without any pretesting. So there is the possibillity that the child may have been suffering from $\mathrm{TBC}$ before vaccination or is in the incubation perilod or that during the incubation period of BCG the child gets infected by the M. tuberculasis. Thils might happen to anyone who have already been vaccinated in the neonatal period. Our 7 patijents wilth neonatal BCG have their source of infection from the homes where they were cared for. Besides there is the possibility that the BCG vaccination has not been effective.

TABLE 3 : Mantoux test performed on 115 TBC patients with $B C G$ scar.

$\begin{array}{cccccc}\text { Mt } & - & & & 3 \\ \text { Mt } & 0.1 & \mathrm{mg} & 10-14 & \mathrm{~mm} & 14 \\ & & & \geqslant 15 & \mathrm{~mm} & 88 \\ & & & \geqslant 20 & \mathrm{~mm} & 59 \\ \text { Mt } & 1 & \mathrm{mg} & 10-14 & \mathrm{~mm} & 3 \\ & & & \geqslant 15 & \mathrm{~mm} & 7 \\ & & & \geqslant 20 & \mathrm{~mm} & 3\end{array}$

From table-3 it appears that the post-BCG Mantoux test performed on children with Koch Pulmonum, for the greater pant had an induration larger than $\geqslant 15 \mathrm{~mm}$, and many of them even $\geqslant 20 \mathrm{~mm}$. Unfortunately we have been unable ito find the results of their Mantoux test before they got BCG vaccination.

E. Roentgenogramis. Chest X-ray photo should be made in PA and Lateral projection on the furst examination, and this procedure should be done technically with the best possible methods. There could be different kinds of abnormalities in the X-ray photos, depending on the type of the primary TBC, such as: pneumonia, swelling of the glands, atelectasils, emphysema, pleural effusilon, etc. From the X-ray photos we could have a strong suspicion of the presence of TBC, onlly if there is a milir ary spread or swelling of the paratracheal gland with or without infiltrattion. Other X-ray abnormalities are not specific, they could be caused by TBC, virus, non-specifile microorganisms, or fungit. So generally a diagnosis of TBC cannot be established bassed on the roentgenogram alone. Even a normal X-ray photo will not exclude the possibility of the presence of TBC.

Zarabi (1971) found that $43 \%$ of his meningitis patients showed normal chest X-ray photos. Normal X-ray photos were also found in $8 \%$ of our meningitis patients. Emery (1950) discovered that only one-third of the patients with milliary TBC (on autopsy) had 
shown a milliary spread on their $X$-ray photos. Unfortunately many people in practice still think that they can establish the diagnosis of TBC based on abnormalitilies in the chest X-ray photos alone. High (1969) said that a roenitgenogram is a valuable aid in establishing the dilagnosils of TBC, but it can also cause confugions if not accompanived with more complete data.

F.Bacteriology. A definite diagnosiis of TBC can only be established if acid-fast bacillit have been found. The examination of sputum on children is not successful, mainly because the sputum is directly swallowed and the amourt of microorganisms in children is usually not large. This necessiitates gasitric lavage to be carried out in the morning for 3 consecutive days. Cultivation of the microorganisms is required, stince a direct smear is not sufficient. Therefore proper faoilities of a bacteriologic laboratory are needed, which require a lot of expenses. Neventheless the results of the cultivation are also unsatisfactory.

Kendig (1972) found that through the best laboratory facilities $50-90 \%$ pasitive results could be made, whereas with moderate laboratory facilities only $25-35 \%$ were found. This means that when using the criteria of positive acid-fast bacilli to declare that a chilld is suffering from TBC, we might loose some $10-75 \%$ of TBC patients in children. To make a diagnosis of primary TBC bacteniologically will be anpractical. Thus the criterila of a TBC case employed by a TBC control program caninot be applised at randiom on child patients. Therefore, establishing a clinical diagnosis is most important, even if this type of diagnosis has its disadvantages.

These bastic principles for TBC diagnasis can be used as a standard. Conditions which could indicate the presence of TBC, but whilch have not yet fulfilled the requirements, are often encountered. In such a case a follow-up of the patcients is very important; a repeated evaluation is necessary after some time.

Survey on 857 children treated in the Pediatric Department of Dr. Soetomo Hospital, Surabaya, 1971 -1974 :

Source of infection present $55 \%$ Physical TBC $\quad 39 \%$ Posiltive Mantoux test . $\quad 94 \%$ X-ray photo: - glandular enlargem ent with or wilthout infiltration $70 \%$ - infilitration $28 \%$ - normal $2 \%$

Bacteriology: not routinelly done

This table shows that the Mantoux tesit and the roentgenogram are very important and are adequate itn establishing a dliagnosis. The source of infectilion is found to be only $55 \%$ posiltive. This may still be improved if 
exploration of the family is carried dure, due to the fact that the faciliout more fintensively. In our depar- ties of our bacteriologic laboratory tment bacteriological examination are still inadequate for serving this has not yet become a routine proce- purpose.

TABLE 4: The basic principles for the diagnosis of tuberculosis

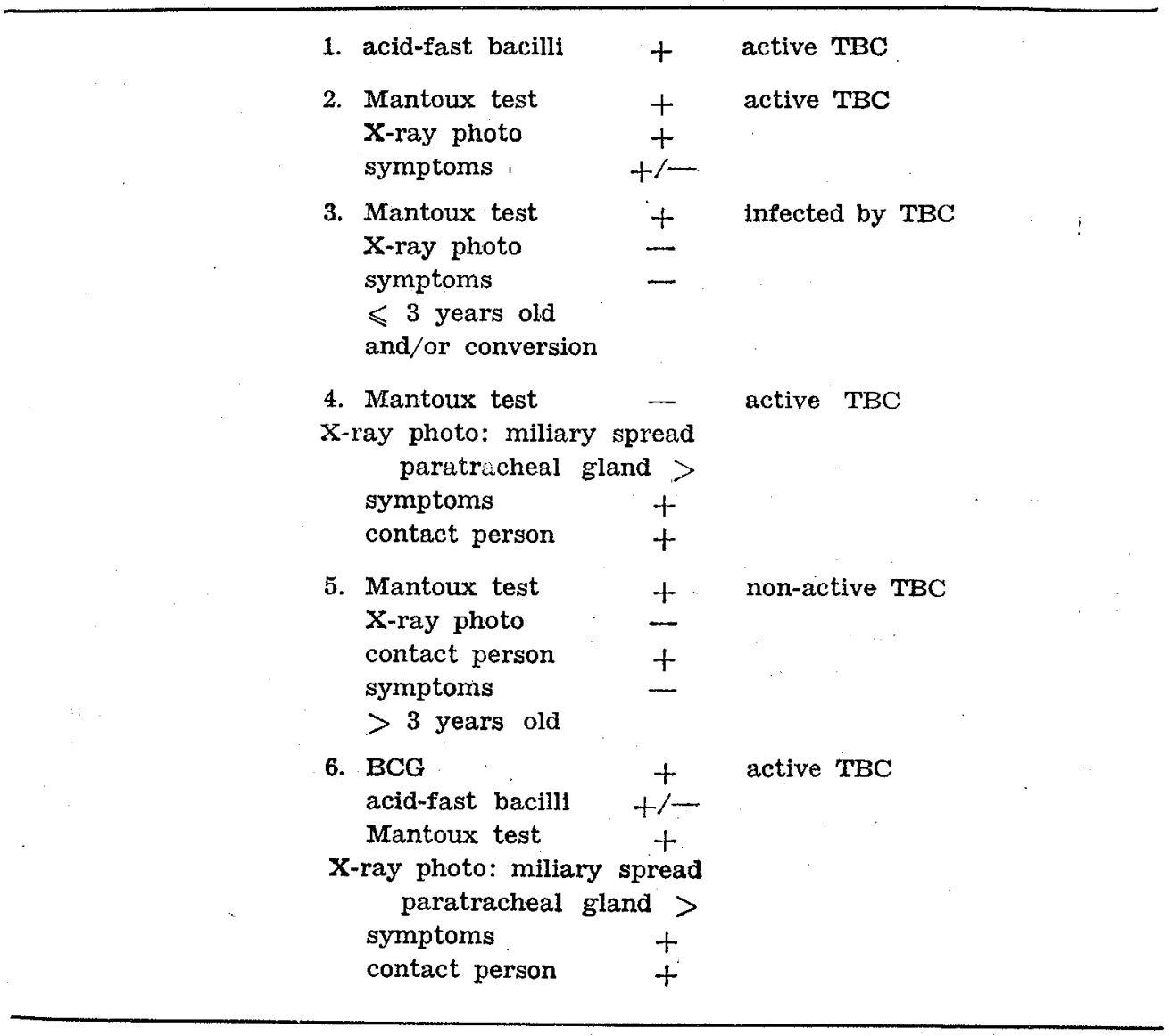




\section{REFERENCES}

1. AZUMA, Y. : Discussion on BCG vaccination. Proceedings VII eastern regional union against tuberculosis, 1972 p. 185 .

2. COMSTOCK, G.W., FURCOLOW, M.L., GREENBERG, R.A., GRYBOWSKT, S., MACLEAN, R.A., BAER, H. and EDWARDS, P.Q. : The tuberculin skin test. Amer. Rev. Resp. Dis. 104 : 769 (1971).

3. Diagnostic standards and classification of tuberculosis, national tuberculosis and respiratory disease association, New York, 1969.

4. EMERY, J.L. and LORBER, J. : Radiological and pathological correlation of miliary tuberculosis of lungs in children. With special reference to choroidal tubercles. Br. med. J. 2 : $702-704$ (1950).

5. GERBEAUX, J. : Primary tuberc1losis in childhood. f(Charles $C$ Thomas Publ., Springfield Tllinois USA 1970).

6. GRIEP, W.A. : Tuberculin conversion. Proc. tuberculosis research council, No. 47, p. 5 - 23 (1960).

7. HASAN M. dan HAN SIK LIANG : Survey tuberkulosis daerah pedusunan. Maj. Kedok. Indones. 9 : 104 (1965).

8. HIGH, R.H. In Nelson's Textbook of Pediatrics. 9th. Asian Edition. p. 594 612. (Saunders, Igaku Shoin Tokyo 1969).

9. HOLT, L.E., Mc INTOSH R., and BARNETT, H.L. : Pediatrics. p. 1212. Thirteenth Edition. (Appleton - Century - Crofts, New York, 1962).

10. JOỌT, Van C.R.N. F. en BLEIKER, M.A. : Epidemiologie van tuberculose en tuberculinehuid gevoelegheid. (Stafleu's . wetenschappelijke uitgevers maatschappij. Leiden, (1966).

11. KENDIG, E.L. Jr. : Pulmonary disorders Vol. I Disorders of the respiratory tract in children. 2nd Edition, (Saunders, Philadelphia, London, Toronto 1972).

12. LANDI, S., HELD, H.R., and TSENG, M.C. : Disparity of potency between stabilized and nonstabilized dilute tuberculin solutions. Amer. Rev. Resp. Dis. 104 : 385 (1971).

13. LIEM TJAY TIE : Tentang tuberkulose kanak-kanak. Berita tuberculosa Indonesiensis. Tahun II: 12-49 (1955).

14. LINCOLN, E.M., and SEWELL, E.M.: Tuberculosis in children (Mc. Graw Hill, New York 1963).

15. LOTTE, A. and PERDRIZTE, S.: Risk of tuberculous infection in newborns tuberculin conversion. Proceedings XIII International Congress of Pediatrics. Vol. 6 : 181 - 189 (1971).

16. MEHTA, J.B., SUKHANI, S.C., SAXENA, $\mathbf{S}$. : BCG vaccination in newborns and tuberculin conversion. Proceedings XIII International Congress of Pediatrics. Vol. 6 : 227 - 232 (1971).

17. RAJU, , V.B. and NARMADA, R, : Evaluation of $B C G$ vaccination in children below six years. A pilot study. Indian Pediatr. $7: 532-540$ (1970).

18. ZARABI, M., SANE, S. and GIRDANY, B.R. : The chest roentgenogram in the early diagnosis of tuberculous meningitis in children. Amer. J. Dis child. 121 : 389 (1971). 